\title{
EL LENGUAJE AUDIOVISUAL EN LOS GRADOS DE COMUNICACIÓN: NUEVA METODOLOGÍA DOCENTE
}

Dolors Bernadasi-Suñé1: Universitat Autònoma de Barcelona. España dolors.Bernadas@uab.cat

Patrícia Lázaroi-Pernias: Universitat Autònoma de Barcelona. España patricia.Lazaro@uab.cat

\section{RESUMEN}

Este artículo presenta la experiencia en la aplicación de un nuevo planteamiento docente para la puesta en marcha de la asignatura Lenguajes comunicativos escritos y audiovisuales, para los Grados de Periodismo y Publicidad y Relaciones Públicas de la Universitat Autònoma de Barcelona. Este proyecto, de carácter innovador, ha buscado aunar tres líneas de trabajo. En primer lugar se sustenta en una nueva concepción teórica del lenguaje audiovisual no directamente vinculada a las características tecnológicas de los distintos medios de difusión, sino a una propuesta comunicativa integrada ofrecida por el multimedia. En segundo lugar, se ha trabajado con el apoyo de TIC a través de plataformas muy familiares para los estudiantes (youtube, google, etc.). Finalmente se ha puesto una atención especial en el equilibrio entre las actividades dirigidas (sesiones teóricas), las supervisadas (seminarios de análisis y producción audiovisual) y autónomas (elaboración en equipos de una web), en una asignatura considerada por el nuevo plan de estudios de perfil teórico.

PALABRAS CLAVE: Lenguaje Audiovisual - Innovación Docente - Nuevas Tecnologías

\footnotetext{
${ }^{1}$ Autor correspondiente

Dolors Bernadasi-Suñé: Profesora del Departamento de Publicidad, Relaciones Públicas y Comunicación Audiovisual. Universitat Autònoma de Barcelona. Barcelona, España.

Correo:_dolors.Bernadas@uab.cat
} 


\title{
THE AUDIOVISUAL LANGUAGE IN COMMUNICATION DEGREES: NEW TEACHING METHODS
}

\begin{abstract}
The article presents the experience in implementing a new approach to teaching the subject Print and Audiovisual Communicative Language' in Journalism and Advertising and Public Relations degrees at the Autonomous University of Barcelona. This innovative project has sought to combine three lines of work. First, based on a new theoretical conception of audiovisual language not directly linked to the technological characteristics of different media. It follows a communicative proposal integrated offered by the multimedia. Secondly, we have worked with the ICT support by well- known platforms for students (youtube, google, etc..). Finally, special attention has been on the balance between activities directed (theoretical sessions), the supervised (seminars on analysis and audiovisual production) and autonomous (development of a website). Not to mention that it is considered a subject of theoretical profile of the new curriculum.
\end{abstract}

KEY WORDS: Audiovisual Language - Teaching Innovation - New Technologies

\section{INTRODUCCIÓN}

El ajuste de los planes de estudio de los nuevos Grados de Periodismo, de Comunicación Audiovisual y de Publicidad y Relaciones Públicas a las exigencias del Espacio Europeo de Educación Superior ha significado una gran oportunidad para el ensayo y la aplicación de nuevas metodologías orientadas a la innovación docente. Este artículo expone la valoración de la puesta en marcha de una nueva asignatura, Lenguajes Comunicativos Escritos y Audiovisuales.

Presentamos el trabajo realizado a lo largo de los cursos académicos 2010-2011 y 2011-2012. El equipo docente ${ }^{2}$ ha orientado su labor hacia el replanteamiento de cómo transmitir los contenidos tradicionales sobre lenguajes audiovisuales adaptándolos a las nuevas exigencias del trabajo didáctico con estrategias afines al llamado Plan Bolonia; así como a una mayor explotación de las TIC, Tecnologías de la Información y la Comunicación, con el objetivo de mejorar y optimizar la relación teórico-práctica del proceso de enseñanza-aprendizaje. 
En líneas generales, cabe afirmar que la preparación de esta nueva asignatura se ha caracterizado por la necesidad de atender a dos importantes diferencias en relación con experiencias anteriores ${ }^{3}$. En primer lugar el paso de una concepción instrumental de los lenguajes audiovisuales que los relacionaba directamente con un medio, a una propuesta comunicativa integrada, multimedia. En segundo lugar, un cambio estructural: el paso a una asignatura de carácter teórico tras años de considerar sus homólogas como de prácticas de laboratorio.

\subsection{Lenguaje audiovisual: el estudio de la imagen y el sonido}

Tradicionalmente, las asignaturas dedicadas a los lenguajes audiovisuales impartidos en la Facultad de Ciencias de la Comunicación de la Autónoma de Barcelona se han abordado desde una perspectiva que podemos calificar de tecnológico-productiva, en la que se ha relacionado fuertemente el estudio del lenguaje con el medio de difusión. Así, en el plan de estudios en vías de extinción se debían cursar asignaturas tales como Teoría y Técnica del Lenguaje Radiofónico o Teoría y Técnica del Lenguaje Televisivo.

Los argumentos son sencillos: la necesidad de una tecnología específica y adecuada para la elaboración y transmisión de mensajes audiovisuales suscita la exigencia de un conocimiento en profundidad de esa tecnología y, sobre todo, de su influencia en las formas expresivas y sus posibilidades o limitaciones creativas y narrativas.

A esta mediación de carácter tecnológico debe añadírsele otra importante variable relacionada: la necesidad de un conocimiento profesionalizado del medio -adquirido a través del aprendizaje y la práctica diaria- que permita un uso eficaz de convenciones y códigos. Es en este sentido, que debía entenderse la necesidad de distinción del lenguaje audiovisual según el medio.

No obstante, el panorama actual dibuja un nuevo mapa en el que los medios tradicionales se renuevan y conviven con nuevas formas de difusión y nuevas estrategias expresivas y narrativas. Internet deviene la plataforma de esta convergencia tecnológica y comunicativa, convergencia que podemos resumir usando un concepto ya ampliamente conocido: el multimedia, es decir, "la integración sincrónica y unitaria de contenidos expresados en diversos códigos, principalmente mediante textos, sonidos e imágenes" (Salaverría, 2001, p. 388). 
La implantación del nuevo plan de estudios nos proporciona la oportunidad para plantear otra forma de acercamiento al lenguaje audiovisual que rompa con la vinculación unívoca a los medios tradicionales y lo ponga al servicio de cualquier necesidad comunicativa. Así pues, presentamos el desarrollo de la asignatura a través de una propuesta de trabajo que deja de supeditarse específicamente a la tecnología de captación y difusión, para, fijándose en los procesos perceptivos y de comprensión que pone en marcha el receptor de los lenguajes comunicativos, apoyarse en el multimedia como plataforma para el proceso de aprendizaje.

Para la presentación y planteamiento de los contenidos desarrollados en la asignatura se recoge la propuesta de Michel Chion y su método de los ocultadores en el que sugiere "un descubrimiento por separado de los elementos sonoros y los elementos visuales, antes de juntarlos de nuevo" (Chion, 1993, p. 174-175). En nuestro caso proponemos en primer lugar el trabajo con la imagen, convencidos que ésta supone mayor reclamo entre los estudiantes, para pasar posteriormente al descubrimiento del sonido y, como conclusión, la suma de ambos, es decir, lo estrictamente audiovisual. No deben olvidarse, además, aspectos de lenguaje escrito en el contexto audiovisual y de composición gráfica, tal y como se plantea la idea de Lenguajes en la asignatura.

\subsection{Características de la asignatura}

En el curso académico 2010-2011, la Facultad de Ciencias de la Comunicación de la Universitat Autònoma de Barcelona pone en marcha los planes de estudios de los Grados de Periodismo, de Comunicación Audiovisual y de Publicidad y Relaciones Públicas. Una de las nuevas materias es Comunicación, considerada de Formación Básica, con 30 créditos ECTS, a impartir en el primer ciclo de todos los Grados. Las asignaturas vinculadas a esta materia son: Historia de la Comunicación, Estructura de la Comunicación, Teorías de la Comunicación, Tecnologías de la Información y la Comunicación, y Lenguajes Comunicativos Escritos y Audiovisuales.

Según los planes de estudios aprobados (ANECA, 2009a), Comunicación se orienta en el Grado de Publicidad y Relaciones Públicas a:

Proporcionar los conocimientos teóricos básicos en los que se fundamenta la reflexión sobre la Publicidad y las Relaciones Públicas en el contexto de las disciplinas de las ciencias sociales. Se proporcionan los saberes propios vinculados a la comunicación publicitaria y de las relaciones públicas para profundizar sobre la realidad de los medios de comunicación, la realidad 
Conocimientos históricos y teóricos básicos en los que se fundamenta la reflexión sobre la comunicación y el periodismo. Análisis de la producción, difusión y recepción de productos informativos y comunicativos en su relación con la realidad social, la responsabilidad y la actividad del profesional en la actualidad.

En cuanto a la disciplina que nos ocupa, se describe como el "Estudio y capacitación en les diversas técnicas y procesos de redacción y locución de mensajes periodísticos/publicitarios para los medios escritos y audiovisuales". Se trata de una asignatura de 6 créditos ECTS con un fuerte componente teórico (el $25 \%$ del esfuerzo docente del estudiante) que se complementa con otras actividades dirigidas, en este caso, de tipo seminario (con un $10 \%)$. A diferencia de las asignaturas sobre lenguajes audiovisuales del plan de estudios anterior, Lenguajes Comunicativos ha dejado de considerarse una materia con prácticas de laboratorio, lo que hace necesario un profundo replanteamiento en las estrategias docentes hasta ahora aplicadas.

Es también importante fijarse en el itinerario formativo que va a seguir el estudiante, iniciándose en Lenguajes comunicativos escritos y audiovisuales. Para el Grado de Publicidad y Relaciones Públicas, el itinerario es el siguiente:

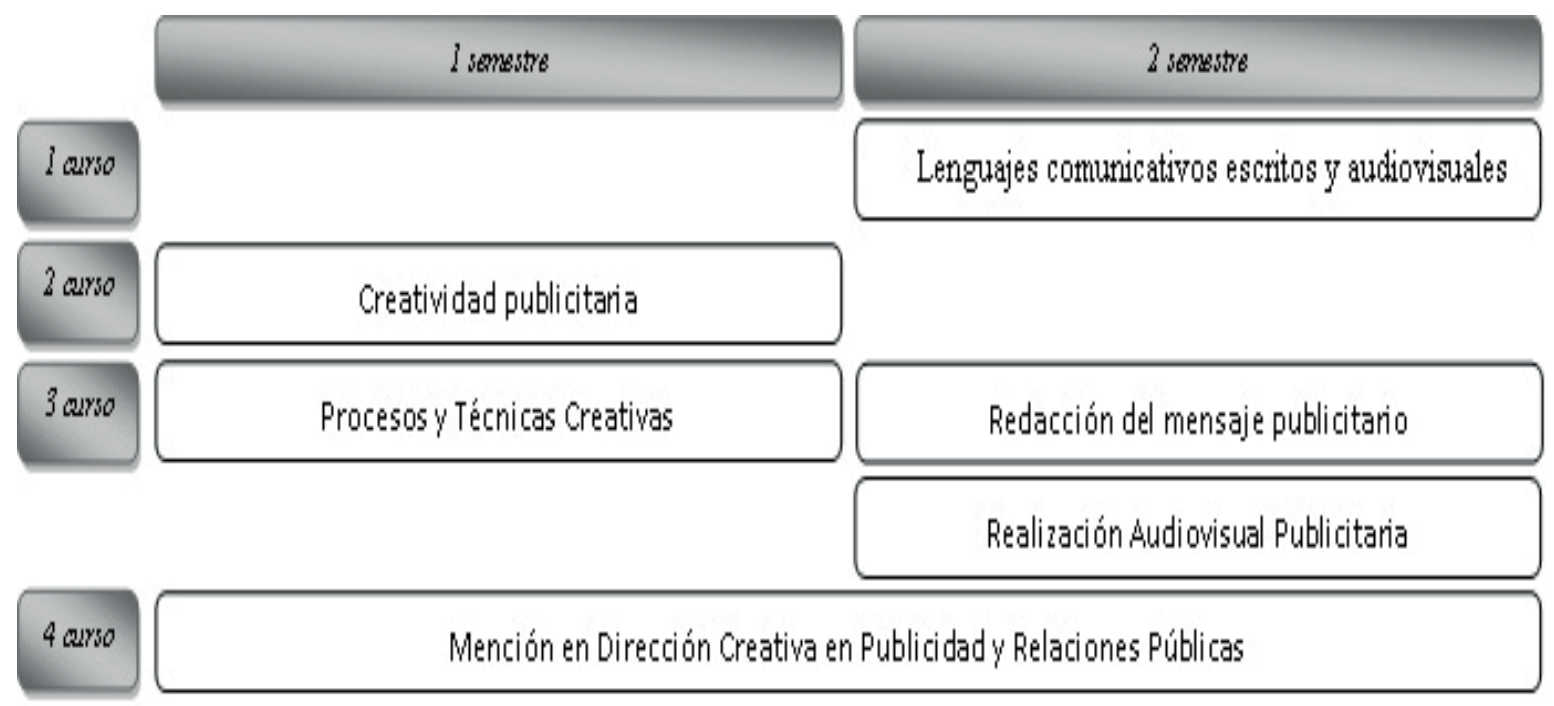

Figura 1. Itinerario Formativo. Grado Publicidad y Relaciones Públicas. Fuente: Elaboración propia 
Y para el Grado de Periodismo:

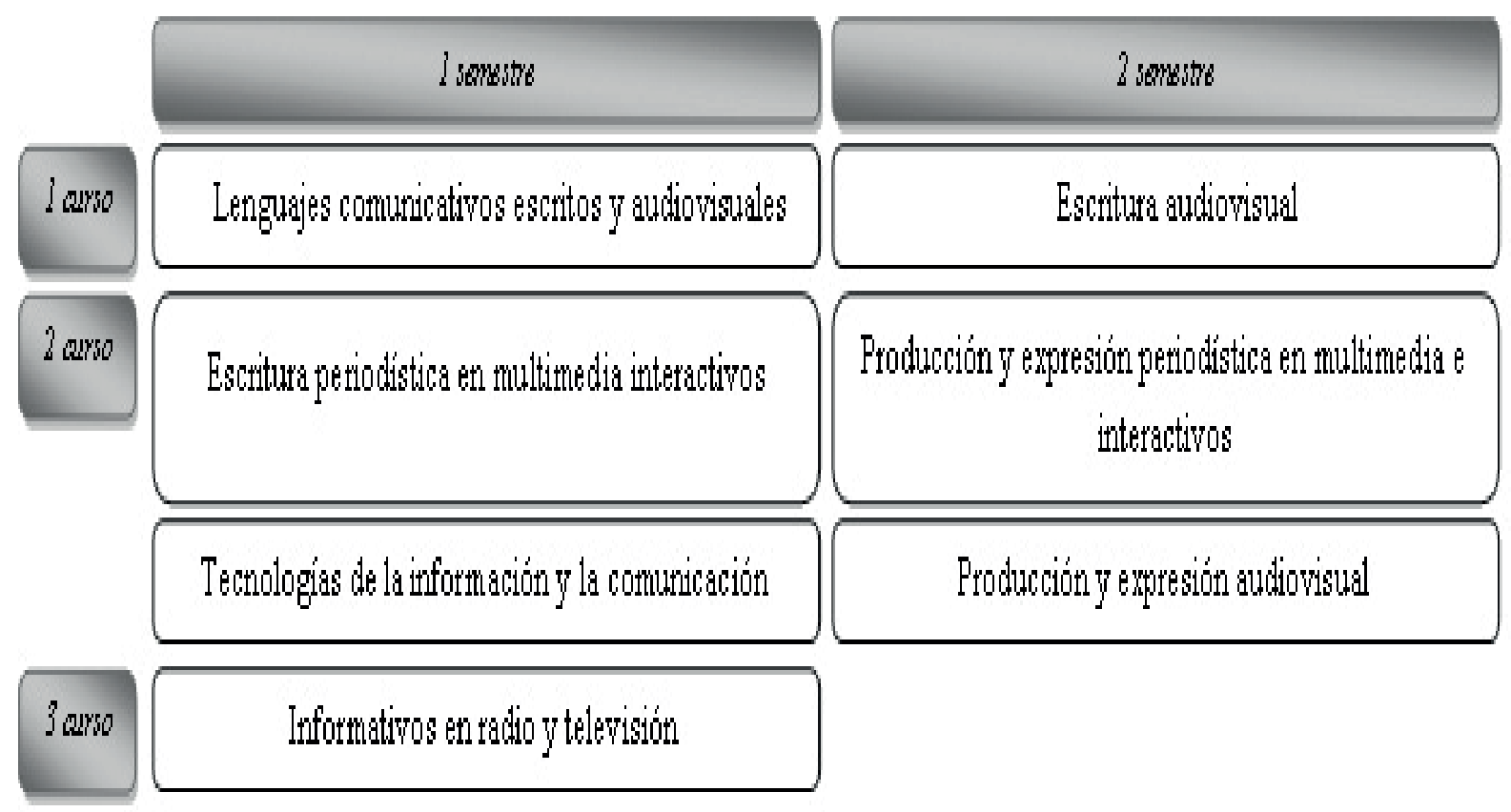

Figura 2. Itinerario Formativo. Grado Periodismo. Fuente: Elaboración propia

A partir del marco general establecido por el plan de estudios de los Grados, y atendiendo a las competencias generales, específicas y transversales a desarrollar, el equipo docente diseña los objetivos de aprendizaje generales. La voluntad de estos objetivos es dotar a los estudiantes de competencias tanto en el ámbito de adquisición de contenidos como de habilidades para capacitarlo en el conocimiento y uso de los lenguajes comunicativos. Tres son los objetivos o metas educativas generales:

a) Adquirir competencias en el conocimiento y uso de los sistemas y recursos expresivos propios de los lenguajes escritos y audiovisuales en el ámbito del periodismo y de la publicidad.

b) Profundizar en los conocimientos relacionados con la imagen y el sonido, vinculados al lenguaje audiovisual, que permitan analizar y evaluar la eficacia de las producciones audiovisuales informativas i/o publicitarias.

c) Adquirir competencias que permitan crear mensajes escritos y audiovisuales aptos para la producción informativa o publicitaria. 
Para fijar los objetivos de aprendizaje específicos, determinar la exigencia de cada uno y poder adaptar el método pedagógico más adecuado, el equipo docente entiende que se halla ante una asignatura que debe enmarcarse dentro del dominio de aprendizaje cognitivo ${ }^{4}$. Por ello toma como marco de referencia la taxonomía propuesta por Benjamin Bloom (Prégent, 1990, p. 34).

Esta taxonomía nos presenta seis niveles de aprendizaje que van desde los contenidos más concretos a los conocimientos más abstractos ${ }^{5}$; cada nivel lleva asociado un tipo de comportamiento cognitivo. En el proceso de enseñanza / aprendizaje de una asignatura compleja como la nuestra proponemos objetivos de cada nivel cognitivo, aunque al ser una asignatura de enseñanza universitaria, los niveles superiores, los más abstractos, serán los que tengan mayor predominio.

a) Adquisición y comprensión de conocimientos:

- Explicar qué es el lenguaje audiovisual, atendiendo a diversos enfoques conceptuales.

- $\quad$ Conocer los sistemas expresivos propios de la imagen y el sonido y describir las principales características expresivas.

- Conocer las características básicas del lenguaje escrito y de la composición gráfica.

b) Aplicación de los conocimientos:

- Planificar montajes audiovisuales eficientes atendiendo a los aspectos básicos de composición y combinación de las formas visuales y/o sonoras y/o textuales.

- Planificar montajes audiovisuales atendiendo al ritmo del producto y a la decodificación del mismo por parte del receptor.

- $\quad$ Organizar la secuencia temporal de una pieza audiovisual.

c) Análisis y síntesis de los conocimientos:

- Relacionar el proceso de creación audiovisual con los aspectos perceptivos y socio-culturales de los receptores.

- Atender a las capacidades perceptivas de los receptores para facilitar la comprensión del montaje audiovisual.

- Escoger el tratamiento narrativo y expresivo más adecuado según el tipo de relato que deba producirse.

- Crear y planificar un relato audiovisual. 
d) Evaluación de los conocimientos:

- Evaluar la eficacia comunicativa de una pieza audiovisual atendiendo a aspectos tecnológicos y perceptivos.

- Justificar la decisión de uso de unos recursos expresivos u otros, según criterios narrativos, expresivos o perceptivos.

- $\quad$ Proponer nuevas formas de tratamiento narrativo y expresivo de un relato que favorezcan la eficacia comunicativa.

\subsection{Experiencia teórico-práctica}

Diversos parámetros, algunos ajenos al propio contenido, marcan el desarrollo de la asignatura de Lenguajes Comunicativos. La brevedad de la inmersión en las dinámicas audiovisuales que ofrece un único semestre de docencia (un promedio de 17 sesiones, de tres horas cada una, dedicadas a la docencia de carácter dirigido o supervisado, es decir, teoría, seminarios y evaluación) y el cambio en la filosofía de la asignatura en el nuevo plan de estudios (práctica antes, teórica ahora) guían, sin duda, el camino a seguir para llevar a buen término el aprendizaje.

El objetivo de los profesores es conseguir que el estudiante participe en clase y se haga responsable de su formación. Que el suyo sea, en definitiva, un aprendizaje activo y cooperativo. Para conseguirlo el equipo docente debe diseñar unos escenarios de aprendizaje para que los alumnos alcancen las competencias propuestas y adaptados a diferentes ritmos de aprendizaje, durante todo el proceso.

Para el diseño de la temporización de contenidos y actividades se ha tenido en cuenta la relación que el plan de estudios establece entre las sesiones de carácter teórico, que aplican un modelo de clase expositiva con análisis de ejemplos y el uso de la pregunta como método participativo ${ }^{6}$; las sesiones de seminario y tutoría ${ }^{7}$, donde se realizan análisis de piezas audiovisuales profesionales y se adquieren técnicas de elaboración de esos productos; y las sesiones autónomas en las que el alumno, como parte de un equipo de producción, lleva a cabo su proyecto de curso.

Además, para neutralizar la dificultad de presentar una materia de forma teórica cuando su contenido y su entorno son eminentemente prácticos, se ha buscado un equilibrio entre la dinámica teórica del método expositivo y las sesiones en pequeño grupo de tutorías y seminarios. 
El aprendizaje a partir de la producción y de la evaluación de productos, donde deben confluir la teoría y su aplicación, tanto en sesiones con presencia del profesor, como en grupos de trabajo sin docente, favorece la experimentación y facilitan la adquisición de rutinas y experiencias del alumno. Por ello se programan actividades dirigidas, supervisadas (tutorías y seminarios) y autónomas. Así pues, en la asignatura de Lenguajes Comunicativos Escritos y Audiovisuales se trabaja en tres ámbitos de entre 20-30 alumnos.

\section{METODOLOGÍA}

La base metodológica se basa en el análisis de las anteriores escuelas de pensamiento que han tratado el tema que nos ocupa. Se trata de analizar los principales medios existentes hoy y aplicarles un método analítico textual que permita producir inferencias fenomenológicas o estructuras de pensamiento novedoso basado en este tipo de reflexiones que crean un puente entre las ideas anteriores (y sus realidades descritas) y las más modernas.

\section{ANÁLISIS Y DISCUSIÓN}

\subsection{Docencia de contenidos teóricos}

Si bien el método expositivo o lección magistral es un método docente que despierta recelos y es valorado negativamente al ser calificado de método que induce a una posición pasiva del estudiante y que provoca el cansancio, entendemos que se trata de una práctica docente que bien planteada y bien desempeñada no hay que desdeñar dado que facilita un aprendizaje activo y cooperativo.

Calificamos de informales a las lecciones magistrales desarrolladas en esta asignatura. Estas clases, si bien se basan en el discurso más o menos continuado del profesor, permiten y fomentan la participación del estudiante ya sea porque interpela al profesor para expresarle sus dudas o reflexiones, ya sea porque es el profesor quien interpela a los estudiantes. La interpelación profesor-alumno, a través del uso habitual de la pregunta es un recurso docente de gran valor.

Otro recurso didáctico ampliamente utilizado son materiales audiovisuales, ejemplos prácticos extraídos de la producción profesional, como ilustración de aquello que se está explicando. Finalmente otro de los métodos utilizados está directamente vinculado al trabajo con la bibliografía. Cuando se estima oportuno se propone a los estudiantes la lectura de alguno de los materiales de la bibliografía obligatoria u otros. De esta manera la clase exnncitiva no se convierte on $11 \mathrm{n}$ esnacio destinado a dar la 


\subsection{Docencia experimental con argumentación teórica}

En diferentes formatos docentes, se analizan diversas piezas extraídas de los medios de comunicación aportando las justificaciones teóricas precisas para defender la coherencia de la pieza. También se resuelven problemas y se proponen instrumentos y recursos didácticos en las sesiones de tutoría y seminario con actividades dirigidas y supervisadas. Con la realización de unos ejercicios previamente definidos, en cada sesión se pretende mejorar la comprensión de los conceptos precisos para llegar a la creación de piezas propias.

Estas sesiones se apoyan en TIC a través de herramientas y plataformas muy familiares para los estudiantes. Los equipos básicos usados son ordenadores con software que permite la edición de audio, vídeo, retoque fotográfico, composición gráfica, edición de textos, creación de páginas web o blogs. En cuanto a acceso y uso de internet, se trabaja con plataformas y hostings de amplia inserción, tales como google, youtube, soundcloud, etc. Además los estudiantes usan todo tipo de dispositivos (desde cámaras de vídeo a teléfonos móviles) de captación de imágenes y sonido, con salidad USB para facilitar el volcado al ordenador.

Los alumnos trabajan de forma individual, por parejas o por equipos, en los siguientes ejercicios propuestos:

a) Plantilla de desglose de imágenes/sonido. Vaciar una pieza audiovisual ayuda a los estudiantes a aprender a mirar y a escuchar, y les permite adquirir y asentar conocimientos en lo que se refiere a la nomenclatura del lenguaje audiovisual, dotándoles de las herramientas básicas para la descripción de las imágenes y el sonido: tipos de planos, ángulos, movimientos, transiciones, para la imagen; planificación sonora, elementos del lenguaje, transiciones, para el sonido.

b) El grado de síntesis que supone plantear toda una pieza en una plantilla y que, a simple vista sea capaz de connotar cómo se sucede la historia, tendrá que servir, también, en el momento de elaborar nuevos productos, como guión previo que en la fase de pre-producción trasvase aquello imaginado al papel, y que en la fase de producción sea capaz de guiar al equipo en la captación de imágenes y/o sonidos.

c) Análisis del lenguaje audiovisual. No es lo mismo medir que argumentar. Si el desglose servía para medir qué pasaba en cada pieza, el análisis debe explicar los porqués de esas decisiones hasta ser capaces de comprender. En los seminarios se analizan algunas piezas (como mínimo una audiovisual $\mathrm{v}$ 
d) A final de semestre se ha programado una prueba de características similares, un análisis que debe reflejar conocimientos teóricos. A este seminario pueden asistir con la documentación que crean pertinente (libros o apuntes). Las respuestas de los alumnos permiten evaluar el grado de interrelación entre los conocimientos teóricos y prácticos.

e) Creación de piezas: audiovisual y sonora, en todas sus fases: preproducción, producción y post-producción.

En la segunda sesión de seminario se pide a los alumnos que escojan un producto determinado para crear una historia sonora y audiovisual (explicativa, en el caso de periodismo y promocional para los alumnos de publicidad). Ambas piezas pasan por todas la fases productivas asesorados por el equipo docente. En horas de clase se procede a la producción y post-producción de las piezas.

\subsection{Resolución de problemas}

Creación por equipos de trabajo de piezas periodísticas / publicitarias que desarrollan el ámbito del lenguaje audiovisual bajo unas directrices determinadas.

Los alumnos trabajan de forma autónoma. Cada pieza deberá acompañarse de la argumentación teórica pertinente que le de solidez.

Se toma como referente la técnica del ABP, Aprendizaje Basado en Problemas que, como define H. Barrows, se trata de un "método de aprendizaje basado en el principio de usar problemas como punto de partida para la adquisición e integración de los nuevos conocimientos" (Morales y Landa, 2004, p. 147). Resolver problemas requiere que los estudiantes se conviertan en protagonistas.

La creación de productos audiovisuales es una actividad creativa y hacerlo en base a los planteamientos propuestos por los docentes, que permiten relacionar las clases teóricas con las prácticas experimentales y con su construcción paralela de las piezas solicitadas, convierten a esos problemas iniciales en unos instrumentos para el aprendizaje que los alumnos deben resolver solos. El ejercicio constituye un ejemplo de relación de diferentes procedimientos y conocimientos teóricos que son necesarios para obtener un resultado concreto.

Los alumnos, integrados en equipos de trabajo, crean una página web (el trabajo se hará a través de la plataforma virtual de Google por su versatilidad y sencillez) que será el soporte de todas las piezas audiovisuales solicitadas: 
a) Composición gráfica y cartel periodístico / publicitario.

b) Imagen fija periodística / publicitaria. 1 o 2 fotografías acompañadas de un único eslogan o lema.

c) Imagen en movimiento periodística / publicitaria. Montaje solo de imágenes en movimiento, con una duración entre 20 segundos y 1 minuto. El montaje no puede incorporar ni voz, ni música, solo sonido ambiente. Se pretende que las imágenes y el montaje hecho con ellas, hablen por sí solas.

d) Pieza de sonido periodística / publicitaria. Montaje sonoro con voz (de los miembros del grupo y de otras personas), música y efectos sonoros, con una duración entre 30 segundos y 1 minuto. Se busca una pieza rica des del punto de vista sonoro, donde se trabajen los distintos elementos y figuras de montaje.

e) Montaje audiovisual periodístico / publicitario. Pieza que trabaje todos los recursos expresivos del lenguaje audiovisual (de imagen y de sonido), con una duración entre 1 minuto y 1 minuto veinte segundos.

f) Textos periodísticos / publicitarios. Cada pieza irá acompañada de un texto periodístico / publicitario escrito que versará sobre la misma temática de la pieza.

Dicha web está sujeta a una revisión exhaustiva donde se apuntan las correcciones necesarias. En la página web final se comprueba si se han seguido las indicaciones y, en caso contrario, qué argumentaciones teóricas se ofrecen. Cabe destacar que la posibilidad que los alumnos encuentren un camino diferente pero adecuado al propuesto por los profesores ya que el lenguaje audiovisual está en constante evolución $\mathrm{y}$, aunque el conocimiento que se explica en clase está consolidado y consensuado por la comunidad científica, se puede aceptar una nueva visión y una nueva ejecución de los estudiantes que conlleve una innovación en el campo del lenguaje.

Con este modelo, la figura del docente adquiere importancia porque su trabajo no implica únicamente impartir clase sino que acompaña a los estudiantes en el proceso de adquisición de competencias del trabajo, entre las cuales cabe destacar aquellas que le proporcionan criterios de actuación y de auto evaluación: "los estudiantes han de conocer claramente cuáles son las pautas de evaluación, pautas que deban ser exclusivamente aquellas que se relacionan con los Objetivos de aprendizaje del programa" (Branda, 2008, p. 15).

El docente es clave para facilitar el aprendizaje auto dirigido con el rol de facilitador del aprendizaje del estudiante. Por otro lado, el alumno se siente parte integrante de todo el proceso educativo $\mathrm{v}$ productivo. 


\subsection{Sistema de evaluación}

Para evaluar el grado de adquisición de conocimientos planteados en el curso (periodismo y publicidad) se han utilizado diferentes instrumentos. Así, la evaluación se hace en base a diversos parámetros y el resultado final es la suma tanto de los trabajos encargados como de otras evidencias de aprendizaje visibles en el grado de participación de los alumnos en las diferentes actividades (teóricas y de tutoríaseminario) dirigidas y supervisadas.

En el valor porcentual de la nota global la participación activa del alumno permite obtener un plus de excelencia (15\%) en el trabajo de la asignatura, mientras el peso fundamental reside en los trabajos individuales o en grupo (85\%). Este saber, ligado directamente a la aplicación práctica de la teoría en diversos trabajos, reparte su valor de la siguiente manera:

a) En grupo: 45\% WEB de información / promoción local. 15\% Memoria de la web: Portafolio on-line que debe contener los documentos de planificación de las piezas audiovisuales (guión previo al rodaje) y la justificación de todas las decisiones tomadas en el uso del lenguaje audiovisual.

b) Individual: 25\% Análisis de una pieza audiovisual.

\section{CONCLUSIONES}

Una vez finalizado el primer curso de implantación de la asignatura y en pleno desarrollo del segundo año, podemos afirmar que en términos generales, la respuesta de los estudiantes es satisfactoria. Aún así, no disponemos más que de un indicador objetivo para evaluar el grado de interés de los alumnos: el éxito en la superación de la materia, que podemos cifrar en más del $95 \%$ para ambos grados. La Universitat Autònoma de Barcelona cuenta con un completo sistema de evaluación de satisfacción de la docencia, pero éste no se ha implantado a la par que los nuevos estudios de grado.

También los profesores se sienten motivados por este nuevo método. La posibilidad de trabajar con nuevas herramientas pedagógicas y apoyarse en TIC, exige una actualización que es valorada positivamente por el equipo docente. Además el progreso en el trabajo en equipo y la coordinación docente han ofrecido un nuevo panorama laboral que ha estimulado a los profesores.

Tal y como se ha afirmado, el rendimiento académico es ligeramente mejor que en años anteriores y la participación e implicación en las sesiones teóricas, de tutoría y 
Aunque se encuentran productos dispares (desde el punto de vista del lenguaje, algunos muy bien construidos y otros que requerirían una revisión profunda y, probablemente, aún más tiempo para la maduración en la adquisición de conocimientos de lenguaje audiovisual) se ha tenido muy en cuenta el trabajo del lenguaje por encima de cuestiones de contenido.

En este sentido, destacamos que la propuesta metodológica favorece la adquisición de competencias relacionadas con el lenguaje audiovisual de forma progresiva y se adapta a los diversos ritmos y habilidades de los estudiantes (ABP).

Entre los aspectos que el equipo docente apunta como cambios imprescindibles para próximas ediciones de la asignatura, cabe destacar la necesidad de hacer un seguimiento del trabajo autónomo de forma más pautada y controlada, y la introducción de actividades individuales que permitan ver la implicación y los aprendizajes de cada alumno en particular.

Finalmente también se planteó la conveniencia de incluir un documento de control sobre los conocimientos básicos previos de los alumnos, tanto des del punto de vista de las herramientas tecnológicas útiles para hacer su trabajo, como del lenguaje audiovisual específico.

La implementación de una encuesta al iniciar el curso (encuesta que ya se ha llevado a cabo en el nuevo curso 2011-20128 ), ha permitido ajustar los contenidos teóricos y las prácticas específicas; así como guiar mejor y más acertadamente a los alumnos en el uso de herramientas y aplicaciones necesarias para la elaboración de sus productos audiovisuales.

\section{REFERENCIAS}

Chion, M. (1993). La audiovisión. Introducción a un análisis conjunto de la imagen y el sonido. Barcelona: Paidós.

Prégent, R. (1990): La preparation d'un cours. Montreal: Éditions del'École Polytechnique de Montréal.

Martínez, M. \& Añaños, E. (2008). Experiències docents innovadores de la UAB. En Ciències socials $i$ en ciències humanes. Bellaterra: IDES-UAB.

Morales B., P. \& Lada F., V. (2004). Aprendizaje Basado en Problemas Based Learning. Theoria, 13: 145-157.Recuperado el 18 de agosto de 2011, de 
Salaverría, R. (2001). Aproximación al concepto del multimedia desde los planos comunicativo e instrumental. Estudios sobre el Mensaje Periodístico, 7: 383-398.

Recuperado el 27 de octubre de 2011, de http://revistas.ucm.es/index.php/ESMP/article/view/ESMP0101110383A/12866.

ANECA. (2009a). Título de Grado en Publicidad y Relaciones Públicas. Barcelona: Universitat Autònoma de Barcelona.

ANECA (2009b). Título de Grado en Periodismo. Barcelona: Universitat Autònoma de Barcelona.

Branda, L. A. (2008). El aprendizaje basado en problemas. Trabajo presentado al Seminario sobre ABP en grupos pequeños y en grupos grandes. Bellaterra.

\section{Dolors Bernadas i Suñé}

Licenciada en Ciencias de la Información (1990). Doctora por la UAB en la especialidad de Nuevas tecnologías: Comunicación Audiovisual (2001). Desde 1994 imparte clases en la UAB en Periodismo, Comunicación Audiovisual y Publicidad, centrando su actividad en el ámbito de los lenguajes radiofónico y televisivo. Como investigadora ha impulsado y desarrollado proyectos dirigidos a la mejora de la práctica y la calidad docente. También ha participado en varios grupos de investigación en proyectos financiados relacionados con la expresión emocional, el análisis instrumental, el uso de la voz y el sonido. Actualmente forma parte de Publiradio, Grup de Recerca en Publicitat i Comunicació Radiofònica.

\section{Patrícia Lázaro i Pernias}

Doctora en Ciencias de la Información por la UAB en 1995. Postgrado en Nuevas Tecnologías y Educación, en 2001. Profesora Titular. Imparte docencia en materias sobre Lenguaje Audiovisual, en especial sobre sonido. Forma parte del Grupo de Investigación en Publicidad (GRP) que actualmente trabaja en dos proyectos financiados (Institut Català de les Dones de la Generalitat de Catalunya. Ha participado en diversos proyectos relacionados con la innovación y la mejora docentes. 